\title{
Impact of Small Scale Irrigation on Resettled Household Food Security: The Case of Hora, Gorrea \& Shenkora Small Scale irrigations in Sasiga District of Wollega, Ethiopia
}

\author{
Habtamu Tolla Shono ${ }^{1}$, Shumet Asefa Kibret ${ }^{2}$ \\ ${ }^{1}$ Project Review Team, Development Bank of Ethiopia, Addis Ababa, Ethiopia \\ ${ }^{2}$ Vice President Academic Research, Mekdela Amba University, Mekdela, Ethiopia \\ Email address: \\ tollahabtamu@gmail.com(H. T. Shono), Shumetasefa@gmail.com (S. A. Kibret) \\ To cite this article: \\ Habtamu Tolla Shono, Shumet Asefa Kibret. Impact of Small Scale Irrigation on Resettled Household Food Security: The Case of Hora, \\ Gorrea \& Shenkora Small Scale irrigations in Sasiga District of Wollega, Ethiopia. International Journal of Ecotoxicology and Ecobiology. \\ Vol. 5, No. 4, 2020, pp. 61-69. doi: 10.11648/j.ijee.20200504.14
}

Received: November 15, 2020; Accepted: December 8, 2020; Published: December 22, 2020

\begin{abstract}
Small Scale Irrigation plays a substantial role in advancing agriculture by increasing productivity and enhancing household food security. The Objective of the study is to see factors affecting resettled farmers' participation decisions in Small scale irrigation and to analyze the impacts of small scale irrigation on household food security. The study used cross-sectional data with a multistage stage sampling technique of 262 and 77 non-irrigation and irrigation user resettled households were interviewed. Binary probit models, Heckman sample selection model two-step is employed in the analysis of the study. The study showed that resettled households with a strong perception on land productivity utilize modern agricultural input, more perception on soil fertility, more access of extension service and with the previous landholding on the site selected for irrigation have more likelihood of participation decision in small scale irrigation than that household with less access and perceptions. Contrary to that resettled households of large land Size holding, more perception on irrigation land repossession and more awareness on irrigation regulation are found to have less likelihood of participation decision in small-scale irrigation. The ordinary least square using adult Equivalent expenditure on food as outcome variable revealed that as Age of resettled households, distance from the market, tropical livestock holding, and crop diversification increases the resettle household food security increases. While Awareness of households on irrigation regulation \& modern farm input utilization was found to harm resettled household food security. As per the study finding holding large land size, less awareness on irrigation regulation, and fear of repossession of irrigation land in case of defaulted farming are found to be the challenging factors to influence resettled household participation decision in small scale irrigation and while as the farmers adopt more input on rain-fed land and develop less awareness on irrigation regulation coping capacity to food security was challenged. This is due to farming input cost escalation, soil fertility deterioration, and poor land preparation, acidisty of the soil due to heavy rain fall and poor crop management practices and hesitation for land reposition incase of irrigation land preparation default. The study recommended a concerned body and stockholders to revisit irrigation regulation for amendment, soil, and water conservation practice to be taken as an intervention package and further study to exceed the scope of the study.
\end{abstract}

Keywords: Small Scale Irrigation, Food Security, Heckman Model, District Sasiga

\section{Introduction}

Agriculture plays an indispensable role in the Ethiopian economy, sources of food for the people, supplies raw material to the industry, and creates a market for the other economic sectors [11]. However, rain-fed dependency, outdated methods of cultivation, low productivity, shortage of rainfall, and pest infestation is the common problem of the sector. Several challenges are confronting Ethiopian agriculture among others drought, limited knowledge on modern agricultural practices and poor infrastructural development are common [3,10]. Rural communities in the drought-prone area develop limited copying capacity of challenging bad weather conditions, particularly during a 
food shortage [18].

To tackle this, the government has launched a food securityenhancing program since 2003 among which resettlement programs, productive safety net programs, household assetbuilding programs, and complimentary community investment programs are common [18]. In the study area, there are resettled communities that have had basic benefit packages set in the program among other farmland and institutional services Small scale irrigation schemes are developed to utilize land during the dry season, hence enhance the resettled household food security. This means the schemes are playing a significant role regardless of certain drawbacks in the management of irrigation land, water, and utilization of improved farm input and cultural practices.

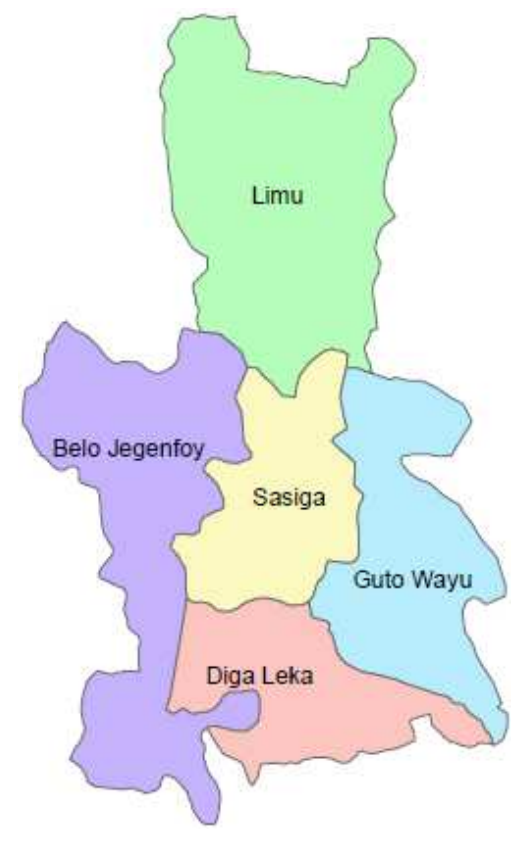

(Depken, 2006)

Figure 1. Map of Sasiga District (Source: Ethiopian Mapping Agency 2018).

\section{Methods and Materials}

\subsection{Study Area}

The study area, Sasiga district is found in Oromia Regional State of Ethiopia $349 \mathrm{~km}$ from Addis Ababa to the West North direction. It is bordered on the south by Diga Leka, on the west by the Benishangul-Gumuz region, on the northwest by Limmu, on the north by an exclave of the BenishangulGumuz Region, and on the east by Guto Wayu. In the district, there are 27 peasant associations and 1 urban town. Among which 8 peasant associations host the resettled communities.

The district has a total of 16,787 households and a population of male $41,326(51.13 \%)$, female 39,458 (48.82\%) of the total 80,814. 78,241 (96.82\%) of these populations living in the rural and the rest 2,659 (3.29\%) are living in the urban area. 16,113 (21.9\%) households and $78,136(96.82 \%)$ of the population members are living in rural areas. The remaining $674(4 \%)$ households 2,659
(3.29\%) populations are living in the urban area [8].

It has an area of 93,813 hectares with topographical features of more gentle sloping plains, flat areas, and small mountain chains. Large parts of the area are covered by organic coffee plantation in the evergreen forest. The altitude ranges between 1500 - 1960 meters above sea level, annual rainfall between $800 \mathrm{~mm}-1200 \mathrm{~mm}$, and temperature $18^{\circ} \mathrm{c}-$ $31^{\circ} \mathrm{c}$. The soil type is characterized by sandy loam, silt, and silt loam; the area has heavy rainfall that largely eroded the soil and devastating soil fertility. Among the types of irrigation [2], the study area is covered by surface irrigation type.

In terms of the command area, irrigation schemes can be categorized in to:

1. Small-scale irrigation system $(<200$ hectares $)$

2. Medium-scale irrigation system (200-300 hectare)

3. Large- scale irrigation system (>300 hectares).

The focus of the study is on small scale irrigation system.

Food Security: Food Security [Is] Situation That Exists When All People, At All Times, Have Physical, Social And Economic Access To Sufficient, Safe And Nutritious Food That Meets Their Dietary Needs And Food Preferences For An Active And Healthy Life [12].

Household: A Household Is A Person Or Group Of People That Acts As A Single Decision-Making Unit [9]. In The Study Context Household Is An Individual Holding Land, Home, And Family Who Takes The Position of Heading Family By Providing Basic Needs From Local Agriculture.

Resettled household Are food insecure households moved from drought-prone areas to rainy areas to equip them with benefits packages of land, food aid, and residential land.

Impact Assessment: project impact assessment can be categorized as ex-post or ex-ante assessment however the focus of the study is ex-post assessment, in contrast to ex-post evaluation, it measures actual impacts accrued by the beneficiaries that are attributable to program intervention. One form of this type of evaluation is the treatment effects model [19, 20, 24, 25].

\subsection{Study Design}

Resettled household-based cross-sectional data was employed for the research study.

Study Population

The study population is households living in three peasant associations where the irrigation schemes are located. These are identified as those possessing irrigated land and those who do not have; commonly called irrigation users and nonirrigation users.

\subsection{Sample Size}

The study used [5] to yield a representative sample for proportions below:

$$
n_{o}=\frac{\mathrm{z}^{2} \mathrm{pq}}{\mathrm{e}^{2}}
$$

Where $n_{o}$ is the sample size, $\mathrm{Z}$ is the abscissa of the 
normal curve (1.96 - equals the desired confidence level, of $95 \%)$, e is the desired level of precision, $p$ is the estimated proportion of an attribute that is present in the population, and $\mathrm{q}$ is $1-\mathrm{p}$.

As per data sources of the district agriculture development office (2018), the target population of the study covered 654 irrigation user households and 2,185 households that are not using small scale irrigation for farm practices. A maximum variably of $\mathrm{P}=0.5$ (maximum variability) is taken as an assumption. Furthermore, it was supposed that a $95 \%$ confidence level and $\pm 5 \%$ precision enables a sound sample size. Accordingly, the resulting sample size is demonstrated below [6].

$$
n_{o}=\frac{z^{2} p q}{e^{2}} \mathrm{n}_{0}=\left((1.96)^{2} \times 0.5 \times 0.5\right) /(0.05)^{2}=385
$$

To slightly reduce the sample size and make a given sample size provide proportionately more information for a small population than for a large population. The sample size $\left(\mathrm{n}_{\mathrm{o}}\right)$ can be adjusted using the following equation [5].

$$
\mathrm{n}=\frac{\mathrm{n}_{\mathrm{o}}}{1+\frac{\left(\mathrm{n}_{\mathrm{O}}-1\right)}{\mathrm{N}}}
$$

Where $\mathrm{n}$ is the sample size and $\mathrm{N}$ is the population size.

$$
n=\frac{385}{1+\frac{(385-1)}{2839}}=339
$$

Where

$\mathrm{n}$ - Adjusted sample size for the target population

$\mathrm{n}_{\mathrm{o}}$ - calculated sample size on the bases of those critical factors

$\mathrm{N}$-is the total population of both irrigation users and nonirrigation users of the peasant associations. As per the allocated sample weight, the study has 77 irrigation and 262 non-irrigation user respondents.

\subsection{Sampling Techniques}

The study employed multistage sampling techniques that resettled peasant associations \& operational small scale irrigation were purposively selected depending on operational schemes, accessibility of the PAs, and easy follow up of the research study. Stratified sampling was employed to classify the sample into two strata irrigation users and non-irrigation users among which $77 \mathrm{HHs}$ from irrigation users and 262 from non-irrigation users were randomly selected.

\subsection{Econometrics Model}

The study employed Heckman's two-step procedure to investigate the impact of small scale irrigation on resettled household food security.

Specification of the Heckman model

The study used Heckman revised version (1979) to specify the model: taking the following form:

$$
Y_{1_{\mathrm{i}}}^{*}=\sum_{\mathrm{k}-1}^{\mathrm{k}} \gamma_{\mathrm{k}} \mathrm{Z}_{\mathrm{ik}}+\mathrm{U}_{\mathrm{i}}
$$

$$
Y_{2 i}=\sum_{s-1}^{s} B_{s} X_{i s}+\varepsilon_{i} \ldots \ldots \text { observed only if } B_{i}^{*}>0
$$

Where,

$Y_{I i}$ - defined a dichotomous variable which takes a value 1 when the latent variable $Y^{*}>0$ and 0 otherwise

$\mathrm{Z}_{i k}$ - is a group of variables $\mathrm{K}$ which represent the characteristics of household $\mathrm{i}$ which determining the decision to participate in the irrigation or not scheme measured by a latent variable $\mathrm{Y}_{\mathrm{i}}^{*}$

$\gamma_{\mathrm{k}}$ are the coefficients which reflect the effect of these variables on this decision; And,

$\mathrm{Y}_{2 i}$ - a dependent variable showing the food security status of the households determined by a group of independent variables

$\mathrm{X}_{i s}$ - is a group of variables $\mathrm{S}$ which represent the characteristics of household $\mathrm{i}$ which determine household food security and

$\beta$ ' ${ }_{s}$ - are the coefficients which reflect the effect of these variables on household food security.

Where: the disturbances $\mathrm{u}_{\mathrm{i}}$ and $\varepsilon_{i}$ follow a bivariate normal distribution with a zero mean, variance $\sigma_{u}$ and $\sigma_{\varepsilon}$ respectively, and covariance $\sigma_{\varepsilon u}$.

In this way, $Y 1_{i}=1$ indicates the decision to participate in the irrigation scheme, and $Y_{l i}=0$ that of not to participate in the irrigation scheme, $\beta$ and $\gamma$ are the vectors of parameters that measure the effect of variables $\mathrm{x}$ and $\mathrm{z}$, respectively. Lambda (inverse Mills ratio) which is related to the conditional probability that an individual household will decide to use (given a set of independent variables) is determined by:

$$
\lambda(-\gamma Z)=\frac{\phi(-\gamma Z)}{(1-\varphi(-\gamma Z)}
$$

Where $\lambda$ is inverse Mills ratio, $\varphi$ and $\Phi$ are density and cumulative distribution function; respectively of the standard normal distribution.

In the second stage of the outcome equation, $\lambda$ is included as an independent variable in the OLS estimates to measures the impact of small-scale irrigation on household food security. The selection control factor $(\lambda(-Z \gamma)$ reflects the effect of all the unmeasured characteristics which are related to the small scale irrigation water use decisions. The model is specified as:

$$
Y_{2_{i}}=X \beta+\sigma_{\varepsilon u}(-\gamma \mathrm{Z})+\mathrm{Vi}
$$

Where $v_{\mathrm{i}}$ is the distributed error term uncorrelated with $X \beta$ and $\lambda(-\gamma z)$

\subsection{Data Collection Procedures}

The study employed both qualitative and quantitative data types for statistical and econometrical analysis. Dummy and continuous variables were used in which variables that are to be expressed in qualitative terms were transformed into some proxy so that it has to be represented and used in regression and numeric variables that have an infinite number of values between any two values were used in the analysis. Secondary 
sources have been collected to support the findings with theories and empirical reviews.

\subsection{Data Processing and Analysis}

For the household survey, a semi-structured questionnaire that contained both open and closed-ended questions was prepared and translated into the vernacular language (Afan Oromo). And pre-testing of the questionnaire was done for validity and reliability. Moreover, two-day training was given for five enumerators including pretesting work. After minor modification was done to the questionnaire final questionnaire was administered on selected sample households residing in the resettle associations. The original data were inserted into Microsoft excel and imported to Stata- Software to employ the selected model for analysis.

\section{Result and Discussion}

The result of the study discusses descriptive statistics and econometric model results on household demographic and socio-economic characteristics, of the selection and outcome variable respectively that the concern is to see the impacts of participation in irrigated farming on resettled household food security.

\subsection{Descriptive Analysis}

\subsubsection{Demographic Characteristics}

Sex and Marital Status of Household Head
As per the research study, 85 percent of irrigation users and 87 percent of non-irrigation users were male-headed while the remaining 15 and 13 percent were female-headed respectively. Regarding their marital status, about 87 percent of irrigation and non-users were married while 9 and 10 percent were divorced and 4 and 3 percent were widowed household heads (Table 1).

Table 1. Sex and Marital Status of Resettled Household Head.

\begin{tabular}{llll}
\hline Description & Sex of Household Head & Frequency & Percent \\
\hline \multirow{2}{*}{ Irrigation User } & Male & 64 & 85 \\
& Female & 13 & 15 \\
Non-Irrigation user & Male & 228 & 87 \\
Description & Female & 34 & 13 \\
& Marital Status & & \\
Irrigation User & Married & 67 & 87 \\
& Divorced & 7 & 9 \\
\multirow{5}{*}{ Non-Irrigation user } & Widowed & 3 & 4 \\
& Married & 67 & 87 \\
& Divorced & 8 & 10 \\
& Widowed & 2 & 3 \\
\hline
\end{tabular}

Source: Own Survey 2019

Age and Education Level Household Heads

The mean age of household head of irrigation users was found to be 41.84 and 41.12 percent for non-irrigation users with a standard deviation of 9.6 and 8.88 percent respectively. The maximum and minimum age for irrigation and non-irrigation users was found to be $26,69,23$, and 68 respectively (Table 2 ).

Table 2. Ages of Surveyed Resettled Household Head.

\begin{tabular}{lllll}
\hline Description & Average age (Yrs.) & St. Deviation & Minimum & Maximum \\
\hline Irrigation user & 41.84 & 9.6 & 26 & 69 \\
Non- irrigation user & 41.12 & 8.9 & 23 & 68 \\
\hline
\end{tabular}

Source: Own Survey 2019

Of the sampled households 67 percent of participants and 82 percent of non-participants were found to be illiterate. The remaining 19 percent of participants households can read and write while 13.6 percent attended primary school.
Concerning non-participants, 4.52 percent of them had a primary school education level, 13 percent can read and write while the remaining 0.38 have secondary education level (Table 3).

Table 3. Education levels of Resettled Household Head.

\begin{tabular}{lllll}
\hline \multirow{2}{*}{ Description } & \multicolumn{2}{l}{ Level of education in percent } & \\
& Illiterate & Read and write & Primary & \multicolumn{1}{c}{ Secondary } \\
\hline Irrigation user & 67 & 19 & 13.6 & 1.4 \\
Non irrigation user & 82 & 13 & 4.52 & 0.38 \\
\hline
\end{tabular}

Source: Own Survey 2019

\subsubsection{Socio-Economic Factors}

Occupation and Economic Activity of Households

As depicted in the table below 97 percent of the family members engaged in on-farm activities while 3 percent of the household family engaged in off- farm income activities in the condition that they fit the labor force. 93 percent of the non-irrigation user households family engaged in on-farm activities and the remaining 7 percent of the non-irrigators family engaged in off-farm activities (Table 4).
Table 4. Resettled Household Family Engaged on-off Farm Activity.

\begin{tabular}{llll}
\hline Household Family & & Frequency & Percent \\
\hline \multirow{2}{*}{ Irrigation user } & Off-farm participants & 14 & 3 \\
& Non-participants & 371 & 97 \\
Non-irrigation & Off-farm participants & 89 & 7 \\
user & Non-participants & 1221 & 93 \\
\hline
\end{tabular}

Source: Own Survey 2019

Land Holdings

Land size of 2.2 hectares was distributed to resettled 
households of which $200 \mathrm{~m}^{2}$ was for a residential house while the remaining 2 ha was granted for farmland. Moreover few of the settled households expand land holding informally from the host community. The study revealed that irrigation householders were found to have 2.2 ha of landholding while Non-irrigation users possess $2.73 \mathrm{ha}$ on average bases.
Among 1.95, 0.25, 1.7, and 0.25 hectare of land were used for crop production by irrigation and rain-fed mode of operation while the remaining land was used for animal grazing and related activities respectively. Non-irrigation users hold more land size than irrigation users.

Table 5. Land Holdings of the Sampled Resettled Households in Hectare.

\begin{tabular}{|c|c|c|c|c|}
\hline Description & I Irrigation user & Non- irrigation user & An Average & t- value \\
\hline Total land area & 2.2 & 2.73 & 2.5 & $3.7841^{*}$ \\
\hline Land used for cultivation & 1.95 & 2.17 & 2.6 & $2.925 *$ \\
\hline Land used for irrigation & 0.25 & - & 0.1 & $2.754^{*}$ \\
\hline Land used for rain-fed & 1.70 & 2.17 & 1.9 & $11.016^{*}$ \\
\hline L Land used for other purpose & 0.25 & 0.56 & 0.4 & $-3.4148 * *$ \\
\hline
\end{tabular}

Source: Own Survey 2019

*,**, Significant at $1 \& 5$ percent

Livestock Holding

As shown in the table below the livestock holdings of the sampled households has a significant difference among irrigators and non-irrigators. Non-irrigators hold 2.9 cattle in comparison to irrigators with average holdings cattle count of 1.42. The mean Sheep/Goat holding of irrigators was found to be 0.25 while the non-irrigator household was 0.45 . Coming to donkey and chicken both farmers hold an insignificant amount. on average it is found to be 0.045 , 0.048 , and 0.019 and 0.025 of the live stokes respectively (Table 6).

Table 6. Major Livestock Holdings of the Sample Resettled Household of the Study Area (TLU)

\begin{tabular}{llll}
\hline Description & Irrigation user & Non-irrigation user & t-value \\
\hline Cattle & 1.42 & 2.9 & $3.9733^{*}$ \\
Sheep/Goat & 0.25 & 0.45 & $1.6049^{*}$ \\
Donkey & 0.045 & 0.048 & $-7.7109^{*}$ \\
Chicken & 0.019 & 0.025 & $-3.0156^{*}$ \\
\hline
\end{tabular}

Source: Own Survey 2019

* Significant at 5\% significance level

\subsection{Econometric Analysis}

\subsubsection{Econometrics Diagnostic Test}

\section{Detecting Multicollinearity}

The study applied the Variance inflation factor (VIF) to detect the strength of Multi-collinearity. As indicated in [22] the larger the value of VIFj, the more" troublesome" or collinear the variable $\mathrm{Xj}$. As a rule of thumb, if the VIF of a variable exceeds 10, which will happen if $\mathrm{R}^{2}$ exceeds 0.9 , that variable is said to be highly collinear. The study found on average VIF value of the variables to 2.59 and $\mathrm{R}^{2}$ ranging 0.34 and found no significant level of Multicollinearity.

Normality Test

The study used statistical methods for assessing the normality distribution of the data under study. The study used the Doorkin Hansen test for normality distribution and found that positive chi-square $\left(\mathrm{x}^{2}\right)$ and Probability of $\mathrm{chi}^{2}=0.0000$ showing for normal distribution of the data under study.

Test for Heteroscedasticity

The Breusch-Pagan- Godfrey test to detect the existence of heteroscedasticity [17]. Under this assumption, if the computed Chi-square $\left(\mathrm{X}^{2}\right)$ exceeds the critical Chi-square $\left(\mathrm{X}^{2}\right)$ at a choice level of significance let 1 and 5 percent assumption homoscedasticity is rejected. In this case, at 19 degrees of freedom and 1 and 5 percent significance level the critical values are 36.1908 and 30.1435 respectively while the observed Chi-square $\left(\mathrm{X}^{2}\right)$ is 32.1093 implying the significance of the value at the 5 percent confidence level.

Overall Model Specification Test

A vital issue in estimating program net impact is selfselection bias. Selection bias results from estimation on a subsample of individuals who have essentially selected themselves for estimation through their decision to participate in a particular program. Several techniques have been developed to correct for this bias, most notably a twostage technique attributed to [20]. And hence, the study applied Heckman's two-step procedure to identify the impact of small-scale irrigation on households' food security from among possible other households' food security influencing factors.

\subsubsection{Empirical Results of the Binary Probit Model}

The starting point for the Heckman selection model is the selection function describing the way resettle households decided to participate in small scale irrigation or not. The model was fit and estimated using a binary probit model [7]. The resettled household demographic, socio-economic characteristics, farm landholding specific and institutional factors that determine participation and extent of participation in small scale irrigation farming was then analyzed. The study indicated that the model was appropriately specified with an overall chi-square of 147.04 that was significant at a $1 \%$ significance level / 99 percent significance. Five of the variables were such as age, sex, and family size of the household head, distance from the market, landholding for replacement, and livestock holding of the household were found to be statistically insignificant with a low p-value. The remaining eight variables were found to be significant to determine the likelihood of household participation in Small scale irrigation farming. 
Table 7. Maximum Likely Hood of Binary Probit Model.

\begin{tabular}{llll}
\hline Variable & Coefficients & Marginal Effects & P-Value \\
\hline Age of House hold Head- (AGHHD) & -0.008 & -0.004 & 0.632 \\
Sex of Households - (SEXHDD) & +0.35 & +0.012 & 0.464 \\
Family Size -(FAMSIZ) & +0.10 & 0.040 & 0.309 \\
Size of cultivable Land (LANDSIZ) -. & -1.07 & -0.010 & $0.016^{* *}$ \\
Perception of household on Soil Fertility-(SOILFERTI) & +0.54 & +0.25 & $0.000^{*}$ \\
Distance from the Water source-(WATDIST) & -0.98 & -0.045 & 0.154 \\
Access to extension Service - (ACCCEXT) & 1.05 & 0.10 & $0.013^{* *}$ \\
Distance from the domestic market (DISTMKT)- & +0.10 & 0.005 & 0.471 \\
Awareness on irrigation regulation- (IREGULA) & -0.94 & -0.030 & $0.094^{* *}$ \\
Land holding on command area (LHONSITE) & 1.72 & 0.23 & $0.007^{*}$ \\
Land for replacement (REPLND)- & -0.26 & -0.06 & 0.339 \\
Livestock holding (LIVESTOCK)- & +0.24 & 0.01 & 0.157 \\
Repossession (IREPOSES)- & -1.1 & 0.001 & \\
Land productivity (LPDVTY) - & +0.10 & 0.046 & $0.002^{* *}$ \\
Modern agricultural input (FARMINPUT)- & 0.01 & 0.0001 & $0.037^{* *}$ \\
\hline
\end{tabular}

Source: Analytical Output of the research study, 2019

$*, * *$ and $* * *$, are significant at $1 \%, 5 \%$, and $10 \%$ level of significance respectively.

Number of observation $=339$

Pseudo $\mathrm{R}^{2}=0.8953$

\subsubsection{Outcome Equation}

The model was found to be statistically significant at a probability of Chi-square $/ \mathrm{X}^{2} / 0.0000$ at 95 percent confidence interval and wild chi-square 1046.90. The inverse mills ration /lamda was negative in sign with the value of 1200.95 rho $-1.00 \&$ sigma +1200.95 , justifying the existence of selection problem and soundness of the model to proceed into OLS.

In this regard, five variables were found to be statistically significant among others' perceptions of households on soil fertility, crop productivity, level of education of the households and distance of the households from the water source, and participation decision of the households in smallscale irrigations are common.

Generally, the relation of these factors in influencing household characters to participate in small-scale irrigation and hence with households' food security, the significance of the variables, and their effect on the output equation discussed here under the following.

1. Access to irrigation (PARTICIP-Y1): Access to irrigation a dummy variable is 1 if a household participates in irrigation and 0 otherwise. It was hypothesized to have a positive relationship with household food security. The study found that as the likely hood of the household participation decision increased by 1 percent the household food security will increase by 2921 Ethiopian Birr (ETB). The variable was statistically significant at p-value 0.000 which shows a strong influence of small-scale irrigation in securing the household food demand. The study of [1] [13] indicated a positive relationship between access to irrigation and food security. This implies that participation in irrigation would enable farmers to diversify crop production by increasing the frequency of cultivation, enhance livestock husbandry, practice multiple cropping, and supplement moisture deficiency of the cultivable land.

2. Distance from the market center (DISMKT): The study hypothesized a positive relationship between the distance of the household from the market and food security. the distance of the household from the market center increased by $1 \mathrm{~km}$ food security of the resettled household increase by more than ETB 10 at p-value 0.075 at 90 percent probability. This implies the distance of the resettled household from the market destination increases the frequency of supplying food products to the market decreases and the amount of food available in the house in the form of stockholding increases then increasing the volume of food remaining for consumption. This reduces the susceptibility of the resettled households to food shortages. It also decreases the time and cost incurred for transportation of out put to and from the market. The other study revealed a negative relationship between the distance from the water and household food security [1].

3. Age of the resettled household head (AGEHHD): As the age of the resettle household increase by 1 year the household food security is expected to increase by 18.50 ETB. This implies as the age of households increases above an average year of the respondents' food security of the resettled household increases. [19] Revealed the same result for the relationship between household food security and age. A resettled household who was screened during the resettlement program got a benefits package during program implementation. Currently, there was no land distribution system for young generations regardless of unemployed youth association in the form small scale.

4. Modern Agricultural Input (FARMINPUT) - As hypothesized the variable was found to influence the behavior of resettled household participation decisions in small-scale irrigation but negatively related to resettled household food security. It was found to be 
statistically significant with 99 probabilities with pvalue $0.007 \mathrm{Z}$ - score -2.12 and coefficient of relation 1.44. The study found that as the resettled household usage of improved agricultural input increased by a unit of ETB food security of the household decreased by 1.44 Ethiopian Birr. This due to escalation in the price of agricultural input and low productivity of the area. In the area as more, the household participated in agricultural input utilization the more they face a challenging condition in the coming harvest. However, Resettled households who use more modern agricultural input are more likely to decide to participate in a given program including irrigation. Contrary to the hypothesis the variable was found to hurt household food security and statistically significant with a p-value of 0.007 at 99 percent probability. The site selected for the resettlement program was owned and cultivated by the former state farm in the dergu regiom. The land is highly deteriorate due to continuous cultivation and intensive utilization of chemical fertilizers. They said that while the saw improved seed with fertilizers it emerge normally, turned into yellow, and later burned or physiologically deteriorated becoming low in yield. Farmers prefer sorghum to maize production, livestock husbandry to grain production to save input costs of production. The said rather than utilizing cereal seed, chemicals, and fertilizer it is better to fatten bull and oxen for the local market. As they stated the amount of grain harvested from production of improved inputs couldn't cover the costs of production and was becoming loss to the farmers and then eroding their asset base. This problem significantly negatively affect the resettled household food security and adoption of new technology unless and otherwise the soil can be treated in either way of technological advancement.

5. Awareness of Irrigation regulation (IREGULA) Irrigation regulation is one of the irrigation management tools to manage and guide proper utilization of the irrigation water and its maintenance. The variable was hypothesized to have a negative influence on the behavior of the households to participate in small-scale irrigation and hypothesized to have a positive impact on household food security. As hypotheses, the variable harms the resettled household participation decision in small-scale irrigation and food security and statistically significant in the case of the participation decision and household food security. The study found that as the likelihood of the resettled household participation decision in smallscale irrigation due to awareness on irrigation regulation increases by 1 percent the resettled household food security will decrease by 344 ETB. The more the household has more awareness of irrigation regulation the less they secure food security less to his/her counter part by 344 ETB. This implies as awareness on irrigation of an individual increased by 1 percent it deducts 344 ETB from his/her pocket challenging food security. This implies that the more the household develops awareness on irrigation the less they participate in small-scale irrigation farming hesitating for the presence of punishment or irrigation land repossession. Farmers believe that if they fail to utilize the acquired land for irrigation government can repossess the land and transfer to another party, even the farmers who participated in SSI change their irrigated land to perennial crops fearing for the case.

6. Crop Diversification: - The study hypothesized that resettled households diversifying crop cultivation are more likely to participate in small scale irrigation and secure household food than non-irrigation users. Compliance with the hypothesis the variable has a positive relationship with the resettled household food security. An increase in one crop type will increase the resettled household food security by Ethiopian Birr 124 and 50 cents. The variable is statistically significant at a 90 percent probability showing that crop diversification determines to resettle household food security. Resettled households of the study area stated that the cultivation of different crops during the rainy season enables improvement of soil fertility while in irrigation farm diversifying crops enable them to increase to have early maturing crops before the rainy season. In doing so the resettled households secure food more than those who do not want to diversify crops. The study of $[1,13,15]$ were found the same result in compliance with this stuy. Table 8 shows the determinant factors affecting the resettled household food security including crop diversification.

Table 8. Determinant Factors affecting Resettled Household Food Security of the OLS Model.

\begin{tabular}{lll}
\hline Variable & Coefficients & P-value \\
\hline Constant & $2,307.34$ & $0.000^{*}$ \\
Participation (Y1) & $2,921.033$ & $0.001^{*}$ \\
AGHDD & 18.51 & $0.005^{*}$ \\
SEX & -84.86 & 0.593 \\
LIT & 57.46 & 0.340 \\
SIZELAND & -9.54 & 0.586 \\
NEWAT & 217.37 & 0.241 \\
ACCEXT & 229.01 & 0.112 \\
DMKTC & 10.32 & $0.075^{* *}$ \\
REGARNESS & -344.97 & $0.035^{* *}$ \\
LHOLDING & 224.09 & 0.195 \\
LIVESTO & 44.22 & $0.077^{* * *}$ \\
CROPDIV & 124.50 & $0.011^{* *}$ \\
FARMINPUT & -1.44 & $0.007 * *$ \\
PLOTDIST & -0.01 & 0.592 \\
DEPRATIO & -34.27 & 0.897 \\
\hline
\end{tabular}

Source: Researcher Own survey 2019

Significant at $1 \% *, * *$ at $5 \%, * * * 10 \%$ level and

Observation- 339

$\mathrm{F}(13,316)=262$

Prob $=0.0000$

R-squared- 0.9128

Adjusted R -squared $=0.9093$

Root $\mathrm{MSE}=913.49$ 


\section{Conclusion and Recommendation}

\subsection{Conclusion}

The purpose of this study was to investigate the impact of small scale irrigation on resettled household food security other variables were investigated which also contributed to the passways through which households pass the decision to either participate or not in small scale irrigations.

Constructive theories briefly emphasized as the behavior of an individual to participate in a given program can be affected by several factors among which demographic, socio-economic, and institutional factors are common. Resettled household participation decision in small scale irrigation is also believed to be influenced by a number of factors. The role of the Irrigation program and its impacts rarely was assessed here in Ethiopia due to lack of field-level data and budget constraint [22]. Some attempts have been made [1, 4, 13-16, 18, 19, 21, 23, 24]. All studies have been conducted under different subtitles some are articles, some are periodical reports while few of them are thesis reports with a similar concept utilizing different models except for [1, 16] using the Heckman selection model for the analysis of the impact of small scale irrigation on household food security.

Based on the study finding household demographic, socioeconomic characteristics, and institutional factors influenced the resettled household participation decision in small-scale irrigation. Besides, resettled households with more access to extension, perception on soil fertility, perception on default repossessing of irrigation land, previous landholding on the site selected for irrigation, and less awareness on irrigation regulation have more tendency of passing decision to participate in small scale irrigation.

Besides it is identified that the more the resettled household believes that small irrigation contributed to livestock husbandry the more they participate in small-scale irrigation. And an increase in land productivity, utilization of modern agricultural input has an impact on the likelihood of the resettle household participation decision. This is an implication for the more the resettled household expects the land to be productive the more they participate verifying for land productivity to be a determinant factor on resettled household participation decisions in small-scale irrigation. The household that adopts modern agricultural technology has more likelihood to participate in small irrigation. Hence it is reasonable to say that modern agricultural input utilization has a positive impact on resettle household participation decisions in small-scale irrigation.

According to the outcome equation, access to small scale irrigation, Age of resettled household, distance from the market center, awareness on irrigation regulation, livestock holding, and diversification of crop and farm input utilization have a positive impact on resettle household food security while the remaining variables have a negative impact. Thus, it is reasonable to say that these variables are determinant factors to affect the likelihood of the household participation decision in small scale irrigation

Participation in small-scale irrigation and awareness on irrigation regulation positively and negatively affect the resettle household food security respectively. Participation in small-scale irrigation improves the frequency of production and harvest which increased production. Awareness of irrigation regulation has a negative influence on resettling household food security. This means the more they aware of irrigation regulation the more they hastate to participate in small-scale irrigation.

Continuous variables such as the age of resettled households, distance from the market livestock holding, and crop diversification were found to positively impact the resettle household food security. While modern farm input utilization was found negatively impacting the resettle household food security.

The final regression output on the household food expenditure regression model revealed that the minimum amount of expense required to meet the calorie recommended daily allowance was Ethiopian Birr 1351.50. However, resettled households participating in small scale irrigation holds 2,899.07 Ethiopian Birr more than non-irrigation users. This shows households who participated in small scale irrigation secure more food than non-participants.

\subsection{Recommendation}

Based on the study result and significance of the variables, recommendations are given here under two sections. The first section presents a set of recommendations to concerned government and non-government organizations. The second section offers a set of recommendations providing suggestions for future researchers to exceed the scope of the study.

\subsubsection{Recommendation and Policy Implication}

All concerned organizations specifically the agricultural development office, cooperative promotion office, Irrigation development office have better strengthen the capacity of resettled farmers and extension agents through the provision of training and awareness creation, particularly on modern agricultural practices, utilization of appropriate input soil and water conservation practices. Since awareness of small-scale irrigation and access to irrigation services are significant in determining the resettled household's participation decision in small-scale irrigation and resettle household food security it is advisable to advocate the benefit of irrigated agriculture over the rain-fed mode of operation.

Road network was one of the benefits packages stated in the settlement program yet the package was not fully implemented but the variable was significant in determining the resettled household participation decision. Also, the significance of distances of households from the market center was identified as it influences the resettled household participation decision in small scale irrigation. Thus concerned unit shall integrally work on the construction and development of road networks. The soil and water conservation practices have to be put in place as an intervention package since the perception of households on soil fertility and land productivity found to determine the resettled household participation decision in small scale irrigation. 


\subsubsection{Recommendations for Further Researchers}

This study provided the first step towards the assessment of small scale irrigation on the food security of resettled households participating and non-participating in the program. The study identified and covered major variables determining the resettle household participation decision in small scale irrigation and the impact of small-scale irrigation on household food security. It is recommended to assess the overall livelihood of the resettled communities against other resettles within the program.

The study found that as the household utilization of modern agricultural input increases the capacity of the household to meet calorie recommended per day decreases. Suitability and mineral contents of the soil have to be investigated and recommendations have better given on the type and rate of fertilizer required to increase land productivity. Contrary to the resettlement benefit package the resettle household was landed on highly deteriorated land in addition to the susceptibility of the area to regional conflict: These are a challenge to the annual bread winning effort of the resettle households: the study, therefore, recommended further researchers to conduct detail study.

\section{References}

[1] Abonesh, T. (2006). The Impact of Small Scale Irrigation on Household: An MSc. Thesis Submitted to Haramya University Scholl of Graduate Studies, Haramaya University, Agricultural Economics, Dire Dawa.

[2] Asawa, G. (2008). Irrigation and Water Resources Engineering. New Delhi: New Age International (P) Limited.

[3] Atsbaha, \& Tesema. (2014). A Review of Ethiopian Agriculture, Roles, Policy And Small Scale Farming System. (K. Dominik Kalweit And William Grech, Ed.) Global Growth Case Book: 37-39.

[4] Bekele, S., Loulseged, M., \& Denekew, A. (2007). Impact of Irrigation on Poverty And Environment in Ethiopia. Colombo, Sri Lanka: International Water Management Institute.

[5] Cochran. (1977). Sampling Techniques. New York.

[6] Kuthary. (2004). Research Methodology. New Delhi: New Age International (P) Limited. Doi: ISBN (13): 978-81-2242488-1.

[7] Christopher Baum. (2005). an introduction to Modern Econometrics Using Stata: Stata Press; Massachusetts.

[8] CSA. (2013). Population Projection of Ethiopia, At Wereda Level From 2014 - 2017. Addis Abeba: Federal Democratic Republic of Ethiopia Central Statistical Agency.

[9] Depken II. (2006). Micro Economics Demystified. New York.

[10] EATA (Ethiopian Agricultural transformation Agency) (2017).
Ethiopian Economy and the Role of Agriculture: Ethiopian Agriculture And Strategies for Growth, 7.

[11] EATA (Ethiopian agricultural transformation agency) (2018). Annual Report 2017/18. Addis Abeba: Ethiopia.

[12] FAO (Food and Agriculture Organization of the United Nations) (2002). The State of Food and Agriculture: Annual Report. Rome.

[13] Fekadu Abdissa (2012). The Impact of Small Scale Irrigation Schemes on Household Food Security in Western Oromiya, Ethiopia: The Case of Sibu Sire District of Eastern Wollega Zone. Haramaya University, Dire Dawa, Ethiopia.

[14] Gadissa Ejigu (2016). The Contribution of Small scale Irrigation to Household Farm Income and Food Security: A Thesis Submitted to College of Agriculture Graduate studies of Harmaya University, Haramaya University, Dire Dawa, Ethiopia.

[15] Getinet Kebede (2011). Linking Small-Scale Irrigation and Household Food Security: A Thesis Submitted to the School of Graduates Studies of Addis Ababa University, Addis Ababa University, School of Graduate Studies, Addis Abeba, Ethiopia.

[16] Gill, M. (2011). Water Management And Food Security: (Chandra. A. Mandramootoo, Ed.) Mc Gill Institute For Global Food Security: Montreal, Canada.

[17] Gujarati, D. N. (2004). Basic Econometric: Fourth Edition: Mcgraw-Hill Companies. New York.

[18] Guush B, (2013). Evaluation Of Ethiopia's Food Security Program: Ethiopia Strategy Support Program II (ESSP II), 912. Addis Ababa, Ethiopia.

[19] Hadinnott, J. (2006). Choosing Outcome Indicators of Household food Security. Technical Guide. 7. USA: International Food Policy Research Institute.

[20] Heckman. (1979, Jan). Sample Selection Bias As A Specification Error. Econometrica, 47, 153-161.

[21] IFPRI (Investments In Irrigation for Global Food Security) (2017). Enabling the Business of Agriculture 2017, 3.

[22] IWMI (International Water Management Institute) (2005). Experiences and Opportunities for Promoting SmallScale/Micro Irrigation and Rainwater Harvesting for Food Security in Ethiopia.

[23] Nahusenay, K. 2. (2015). Small-Scale Irrigation: The Driver for Promoting Agricultural Production. Irrigation \& Drainage Systems Engineering, Department of Cooperative Studies, College of Business And Economics, Mekelle University, Ethiopia Department of Geography, Ghent University, Belgium. Brasells: Ghent University.

[24] Tilahun, H. (2011). Comparative Performance of Irrigated and Rainfed Agriculture in Ethiopia. World Applied Sciences Journal 14 (2): 235-244, 2011, 239.

[25] White, \& Raitzer. (2017). Impact Evaluation of Development Interventions: A Practical Guide: Asian Development Bank. Manila. 